\title{
Modulation of SAPO-34 Property with Activated Seeds and Its Enhanced Lifetime in Methanol to Olefins Reaction
}

\author{
ZHANG Dongqiang, LU Huihui, SU Na, LI Guixian, JI Dong, ZHAO Xinhong \\ (School of Petrochemical Engineering, Lanzhou University of Technology, Lanzhou 730050, China)
}

\begin{abstract}
Solvent-free synthesis of zeolites has received extensive attention in recent years, because it is advantageous over conventional hydrothermal synthesis. Nevertheless, SAPO-34, a micropore zeolite, prepared by this method does not satisfy the catalytic lifetime requirements of the methanol-to-olefins (MTO) reaction. Herein, an improved solvent-free approach was developed to synthesize SAPO-34 catalysts with enhanced MTO reaction performance, in which acid-etched seed crystals were introduced to modulate the physico-chemical properties of the zeolite via crystallization kinetics regulation. The results indicated that the SAPO-34 samples prepared from seed-containing precursor gels show considerably higher crystallinity, larger surface area, but lower strong acid site density than the parent sample. In particular, the catalytic lifetime of the SAPO-34 catalyst prepared from activated seeds was remarkably prolonged to $480 \mathrm{~min}$, which was significantly superior to that of the parent sample (40 min). The result confirmed the validity of the seeding approach for modifying the zeolite properties via the solvent-free synthesis and the potential of the approach in improving catalytic performance.
\end{abstract}

Key words: SAPO-34; methanol to olefins reaction; solvent-free synthesis; activated seeds

Zeolites with uniform micropores, tunable acidities, and high thermal/hydrothermal stability are important heterogeneous acidic catalysts in the petrochemical and fine chemical industries ${ }^{[1-3]}$. In recent years, as a successful alternative route of producing light olefins via a nonpetrochemical approach from the abundant resources of coal, natural gas, and even biomass, the zeolitecatalyzed methanol-to-olefins (MTO) reaction has gained considerable attention from academic and industrial communities $^{[4-8]}$. After extensive experimentation using various molecular sieves, it was demonstrated that smallpore 8-membered ring (8-MR) molecular sieves served as excellent catalysts in the MTO reaction $(100 \%$ methanol conversion $)^{[9]}$. In particular, silicoaluminophosphate zeolite SAPO-34 with the CHA topological structure showed high selectivity to light olefins (over 90\%) for this reaction because of the presence of $3 \mathrm{D}$ channels in its structure and moderate acid strength ${ }^{[10-15]}$. However, the main problem associated with the SAPO-34 catalyst was the rapid deactivation during the MTO reaction due to the formation and trapping of heavy secondary products (coke) within the pores (channels and cages) ${ }^{[16-18]}$.
For the SAPO-34 catalyst, its deactivation in the MTO reaction is closely related to its acidity. It was reported that Brønsted acid sites played a critical role as active sites in this catalytic process ${ }^{[19]}$. On one hand, the Bronsted acid sites facilitate the generation of cyclic carbenium ions and aromatics during the induction period, which then serve as hydrocarbon pool species on the working catalyst ${ }^{[20]}$. On the other hand, coke compounds, i.e., large polycyclic aromatics, are formed at the Brønsted acid sites with further progress of the reaction, eventually causing catalyst deactivation ${ }^{[17-18,21]}$. Numerous studies have revealed that the coke rate increases with stronger acid sites and higher acid site density. Therefore, the SAPO-34 catalyst with mild acid strength and relatively low acidity density should be more appropriate for the MTO reaction. As such, various strategies have been developed for controlling the acid sites to obtain the highly active SAPO-34 catalyst with a long lifetime. These strategies include adjusting the silicon content ${ }^{[22-24]}$, metal heteroatom modification (by isomorphous substitution of heteroatoms, ion exchange, or impregnation ${ }^{[25-29]}$, silanation ${ }^{[30-31]}$, seed-assisted synthe-

Received date: 2020-02-08; Revised date: 2020-03-28; Published online: 2020-06-09

Foundation item: National Natural Science Foundation of China $(21666018,21666019)$

Biography: ZHANG Dongqiang(1981-), male, associate professor. E-mail:zhangdq@lut.edu.cn 张栋强(1981-), 男, 副教授. Email: zhangdq@lut.edu.cn

Corresponding author: ZHAO Xinhong, professor. E-mail: licpzhaoxh@lut.edu.cn 赵新红, 教授. E-mail: licpzhaoxh@lut.edu.cn 
sis $^{[32]}$, and recently reported low-temperature synthesis approach $^{[33]}$. Among these strategies, seed-assisted synthesis was probably the most intriguing one because the seeding approach has been proven to own a high capability of modulating the physico-chemical properties of zeolites by changing the crystallization kinetics.

Very recently, Xiao's group reported the solvent-free synthesis of SAPO-34, which exhibited many advantages such as reduced waste production, increased zeolite yield, and extremely low autogenous pressure ${ }^{[34-35]}$. However, the catalytic lifetime of SAPO-34 in the MTO reaction was only $200 \mathrm{~min}$, which did not meet the strict industrial demand ${ }^{[35]}$. In this study, a facile seed-assisted solvent-free method was developed to synthesize SAPO34 by using acid-etched seed crystals in order to modulate the physico-chemical properties of the zeolite.

\section{Experimental}

\subsection{Chemicals and materials}

Pseudoboehmite $\left(\mathrm{Al}_{2} \mathrm{O}_{3}, 72 \mathrm{wt} \%\right.$, Shandong Zibo Chemical Reagent Company), fumed silica $\left(\mathrm{SiO}_{2}, 100 \mathrm{wt} \%\right.$, Aladdin Reagent), diethylamine (DEA, 99wt\%, Tianjin Kaixin Chemical Industry Co., Ltd.), phosphoric acid $\left(\mathrm{H}_{3} \mathrm{PO}_{4}, 85 \mathrm{wt} \%\right.$, Yantai Shuangshuang Chemical Reagent Co., Ltd.), and distilled water were used in this study.

\subsection{Activated seed crystals}

The seed crystals were synthesized under hydrothermal conditions according to the literature ${ }^{[36]}$. The activated seeds were prepared via acid etching with various concentrations of $\mathrm{H}_{3} \mathrm{PO}_{4}$ solution $(0.1,0.01,0.001$, and $0.0001 \mathrm{~mol} / \mathrm{L}$ ). The detailed procedure was as follows. First, $0.25 \mathrm{~g}$ of calcined seeds was slowly added to $\mathrm{H}_{3} \mathrm{PO}_{4}$ solution $(50 \mathrm{~mL})$ and stirred at room temperature for $30 \mathrm{~min}$. After this mild etching process, the solid product was collected by centrifugation and thoroughly washed with distilled water followed by ethanol. Finally, the solid product was dried at $110{ }^{\circ} \mathrm{C}$ for $2 \mathrm{~h}$.

\subsection{Seed-assisted synthesis of SAPO-34 catalysts}

The parent SAPO-34 sample (SP34) was prepared under solvent-free conditions with the molar composition of $1.0 \mathrm{Al}_{2} \mathrm{O}_{3}: 0.6 \mathrm{SiO}_{2}: 1.1 \mathrm{DEA} \cdot \mathrm{H}_{3} \mathrm{PO}_{4}$ according to the patent ${ }^{[37]}$. The procedure for the seed-assisted synthesis of SAPO-34 catalysts was similar to that of SP34 except that specific seed crystals were introduced in the former syntheses. First, $0.85 \mathrm{~g}$ of pseudoboehmite, $0.216 \mathrm{~g}$ of fumed silica, $1.128 \mathrm{~g}$ of solid compounds of diethylamine phosphoric acid $\left(\mathrm{DEA} \cdot \mathrm{H}_{3} \mathrm{PO}_{4}\right), 0.084 \mathrm{~g}$ of various seeds $\left(20 \%\right.$ of the total mass of $\mathrm{Al}_{2} \mathrm{O}_{3}, \mathrm{P}_{2} \mathrm{O}_{5}$, and $\mathrm{SiO}_{2}$ in the raw materials) were mixed together and ground for $15 \mathrm{~min}$. Then, the thoroughly mixed mixture was transferred to a $50 \mathrm{~mL}$ Teflon-lined stainless autoclave and crystallized at $200{ }^{\circ} \mathrm{C}$ for $48 \mathrm{~h}$. Finally, the crystallized SAPO-34 samples were washed with distilled water and dried at $80{ }^{\circ} \mathrm{C}$ for $24 \mathrm{~h}$. All samples were calcined at $550{ }^{\circ} \mathrm{C}$ for $5 \mathrm{~h}$ to remove the template. The resultant products were designated as SP34 (parent

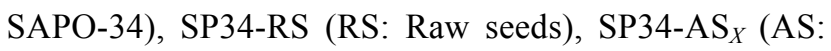
Acid-etched seeds, $X$ : concentration of $\mathrm{H}_{3} \mathrm{PO}_{4}$ solution used to activate seed crystals, i.e., 0.1, 0.01, 0.001, $0.0001 \mathrm{~mol} / \mathrm{L})$.

\subsection{Characterizations}

The phase purity and crystallinity of samples were characterized through powder X-ray diffraction (XRD) patterns obtained from a D/Max-2400 Rigaku diffractometer with $\mathrm{CuK \alpha}$ radiation operated at $40 \mathrm{kV}$ and $150 \mathrm{~mA}$. The crystallinities of SAPO-34 samples were calculated according to the intensity of peaks at $2 \theta=9.5^{\circ}$, $12.8^{\circ}, 20.5^{\circ}$, and $30.5^{\circ[36]}$. Scanning electron microscopy (SEM) images were recorded with the JSM-6701F instruments equipped with energy dispersed spectroscopy (EDS) to observe the morphology and crystal size of SAPO-34. Nitrogen adsorption/desorption measurements were carried out on a Micromeritics 2020 analyzer at $-196{ }^{\circ} \mathrm{C}$ after the samples were degassed at $350{ }^{\circ} \mathrm{C}$ in vacuum. The Brunauer-Emmett-Teller (BET) surface area was calculated from the linear part of the BET plot by the IUPAC recommendation. A Micromeritics AutoChem II 2920 automated chemisorption analysis unit was used for conducting temperature programmed desorption of ammonia ( $\left.\mathrm{NH}_{3}-\mathrm{TPD}\right)$ experiments to characterize the acidity of the samples.

\subsection{Catalytic reaction}

The MTO reaction was carried out in a quartz tubular fixed-bed steel reactor with a length of $30 \mathrm{~cm}$ and an inner diameter of $6 \mathrm{~mm}$ under atmospheric pressure. For each test, $0.3 \mathrm{~g}$ of catalyst was packed in the center of quartz wools. Before the catalytic reaction, the sample was pretreated in a $\mathrm{N}_{2}$ flow of $30 \mathrm{~mL} / \mathrm{min}$ at $500{ }^{\circ} \mathrm{C}$ for $1 \mathrm{~h}$ and then cooled to the reaction temperature. The reactant, methanol, was fed by passing the carrier gas $\left(\mathrm{N}_{2}\right.$, $15 \mathrm{~mL} / \mathrm{min}$ ) into the reactor at $400{ }^{\circ} \mathrm{C}$, which resulted in the weight hourly space velocity (WHSV) of $2.0 \mathrm{~h}^{-1}$. The effluent products were detected by an online gas chromatograph GC7900 system (Tianmei, Shanghai, China) equipped with a flame ionization detector (FID) and Plot-Q column.

\section{Results and discussion}

XRD patterns of SP34, SP34-RS, and SP34-AS ${ }_{X}$ are 
displayed in Fig. 1. All samples exhibited typical diffraction peaks assigned to the CHA structure. However, a significant difference in crystallinity can be clearly observed. The crystallinities of SP34-RS and SP34-AS ${ }_{X}$ was evidently higher than that of SP34 (Fig. S1), demonstrating that the addition of seed crystals can effectively accelerate the nucleation and growth of SAPO-34 crystals.

Fig. 2 exhibits the SEM images of SP34, SP34-RS, and SP34-AS ${ }_{X}$. Sample SP34 presents irregular aggregate morphology of approximately $8 \mu \mathrm{m}$, which consists of diverse micrometer- and nanometer-sized SAPO-34 crystals with a rough surface. When seed crystals were added, the obtained samples (SP34-RS and SP34-AS ${ }_{X}$, $X=0.1,0.01,0.001,0.0001)$ were inter-grown with micrometer- and nanometer-sized smooth SAPO-34 crystals, especially for the SP34-AS ${ }_{X}$ samples. Accordingly, the number of isolated well-shaped crystals was less. The abundant intergrowth could be attributed to the presence of crystal seeds, which governed the growth of SAPO-34

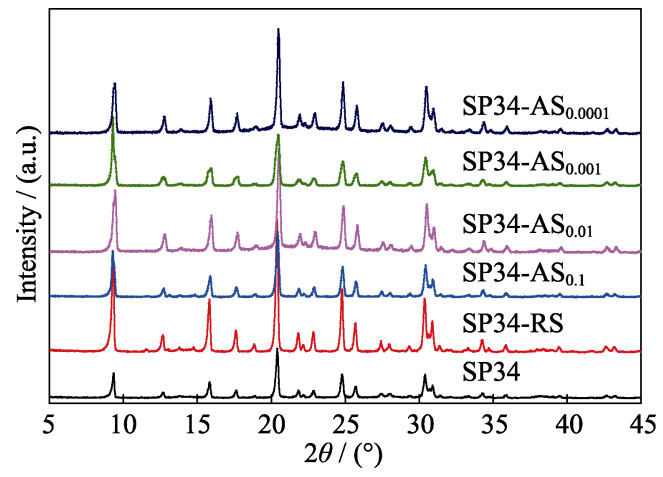

Fig. 1 XRD patterns of SAPO-34 synthesized with different types of seeds crystals, while the low number of single isolated crystals can be explained by limited breeding ${ }^{[38]}$. It was worth noting that the crystal sizes of samples with seeds were larger than those of SP34. The difference in crystal size could be ascribed to the crystallization of SAPO-34 only occurs on the surface of the seeds, thus the primary particle becomes larger than seeds, which is consistent with the results of Tang's group ${ }^{[39]}$.

The physico-chemical properties of all samples are summarized in Table 1, $\mathrm{N}_{2}$ adsorption/desorption isotherms and corresponding pore distribution curves are depicted in Fig. 3 and Fig. S2, respectively. As shown in Fig. 3, SP34 displayed a type IV isotherm, revealing the presence of abundant mesopores. The presence of a hysteresis loop in the relative pressure range of $0.4<p / p_{0}<1$ is typical for such stacking materials ${ }^{[40]}$. The pore size distribution of SP34, with a maximum of around $4 \mathrm{~nm}$ and the texture data in Table 1 unambiguously illustrate that this sample is a material with more mesoporous and less microporous. In comparison, the samples prepared by seed-assisted synthesis (SP34-RS, SP34-AS S $_{X}$ ) exhibited the type I isotherms characteristic of a purely microporous zeolite. In particular, it can be seen from Table 1 that the BET surface area and micropore volume of the SP34-AS $\mathrm{S}_{X}$ samples, comparable to the texture parameter in the literature ${ }^{[15,32]}$, however, were much higher than those of SP34. For the SP34-AS ${ }_{X}$ samples, their enhanced microporosity may be attributed to the increased crystallinity, as determined by XRD. In contradiction with what we expected, the microporous surface of SP34-RS was not the largest, although its crystallinity was the highest among the six samples.

The acid site density and strength of the six samples
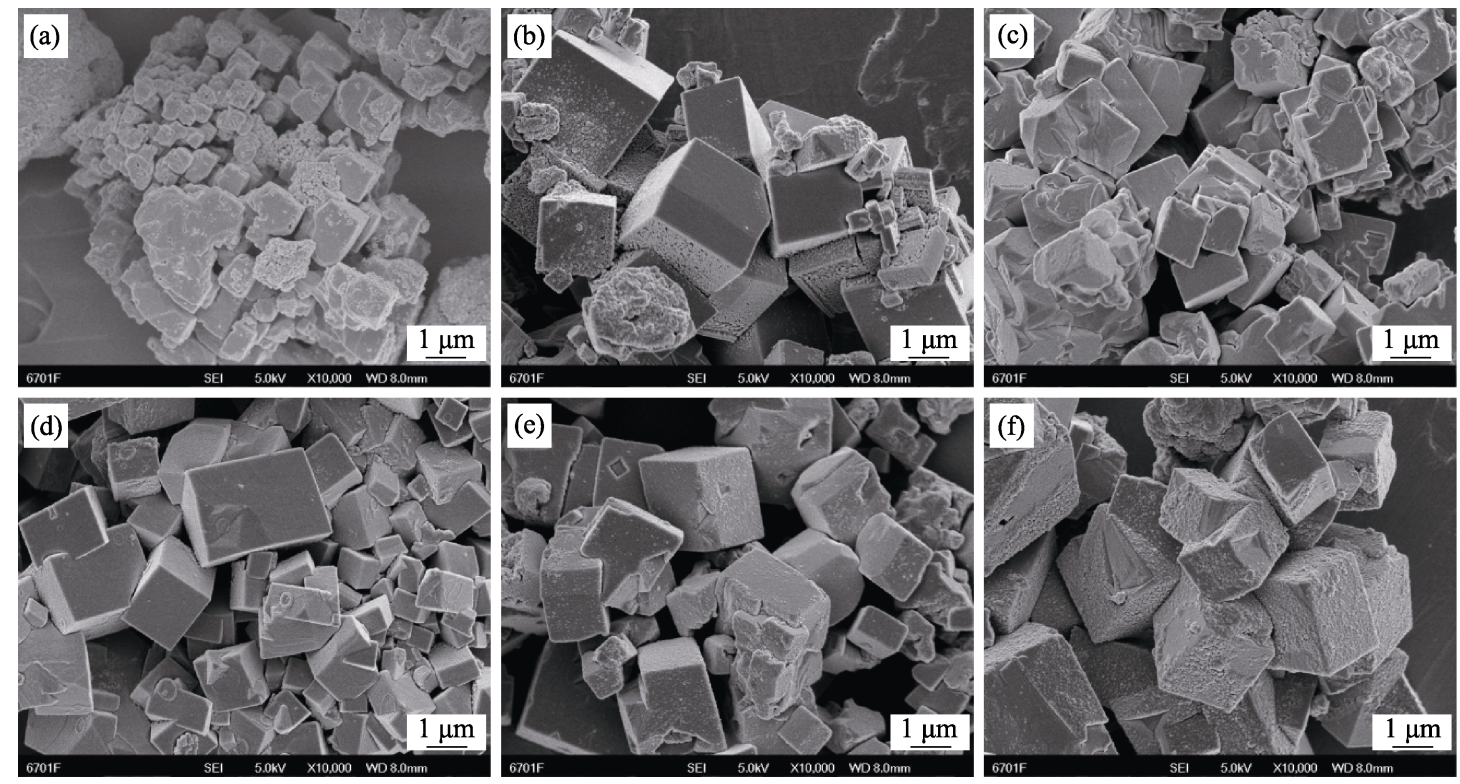

Fig. 2 SEM images of samples in the presence of various types of seeds (a) SP34; (b) SP34-RS; (c) SP34-AS 0.1 ; (d) SP34-AS 0.01 ; (e) SP34-AS 0.001 ; (f) SP34-AS 0.0001 
Table 1 Textural properties, acid amount and catalytic lifetime of different samples in MTO reaction

\begin{tabular}{|c|c|c|c|c|c|c|c|c|c|}
\hline \multirow[b]{2}{*}{ Sample } & \multicolumn{5}{|c|}{ Textual properties } & \multicolumn{3}{|c|}{ Acid amount ${ }^{c}$} & \multirow{2}{*}{$\begin{array}{l}\text { Lifetime } \\
\text { /min }\end{array}$} \\
\hline & $S_{\mathrm{BET}} /\left(\mathrm{m}^{2} \cdot \mathrm{g}^{-1}\right)$ & $S_{\mathrm{mic}} /\left(\mathrm{m}^{2} \cdot \mathrm{g}^{-1}\right)$ & $S_{\mathrm{ext}} /\left(\mathrm{m}^{2} \cdot \mathrm{g}^{-1}\right)$ & $V_{\mathrm{mic}}{ }^{\mathrm{a}} /\left(\mathrm{cm}^{3} \cdot \mathrm{g}^{-1}\right)$ & $V_{\text {meso }}{ }^{\mathrm{b}} /\left(\mathrm{cm}^{3} \cdot \mathrm{g}^{-1}\right)$ & Weak & $\begin{array}{l}\text { Medium } \\
\text { and strong }\end{array}$ & Total & \\
\hline SP34 & 250 & 68 & 182 & 0.029 & 0.342 & 2.77 & 5.37 & 8.14 & 40 \\
\hline SP34-RS & 316 & 291 & 24 & 0.136 & 0.068 & 0.86 & 2.05 & 2.91 & 100 \\
\hline SP34-AS ${ }_{0.1}$ & 547 & 530 & 17 & 0.247 & 0.057 & 0.97 & 2.55 & 3.52 & 480 \\
\hline SP34-AS 0.01 & 552 & 532 & 20 & 0.249 & 0.056 & 1.42 & 3.41 & 4.83 & 300 \\
\hline SP34-AS ${ }_{0.001}$ & 568 & 553 & 15 & 0.254 & 0.052 & 0.85 & 2.20 & 3.05 & 420 \\
\hline SP34-AS ${ }_{0.0001}$ & 568 & 547 & 21 & 0.256 & 0.049 & 1.27 & 3.15 & 4.42 & 330 \\
\hline
\end{tabular}

${ }^{\mathrm{a}} t$-plot micropore volume; ${ }^{\mathrm{b}} \mathrm{BJH}$ adsorption cumulative volume of pores between 1.7 and $300 \mathrm{~nm}$; ${ }^{\mathrm{c}}$ Peak area integral according to $\mathrm{NH} \mathrm{H}_{3}$-TPD profile

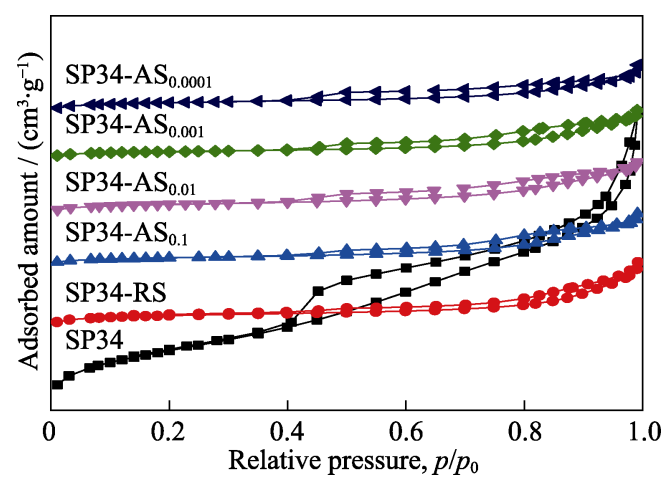

Fig. $3 \mathrm{~N}_{2}$ adsorption/desorption isotherms of SP34, SP34-RS and $\operatorname{SP} 34-\mathrm{AS}_{X}(X=0.1,0.01,0.001,0.0001)$

were examined through $\mathrm{NH}_{3}$-TPD measurements. As shown in Fig. 4, each of the $\mathrm{NH}_{3}$-TPD profiles showed only one asymmetrical desorption peak centered at $\sim 161{ }^{\circ} \mathrm{C}$. After suitable deconvolution (Fig. S3), the peak can be divided into two distinct desorption peaks, corresponding to weak acid sites and medium strong acid sites ${ }^{[41-42]}$. The low-temperature peak was attributed to the desorption of physisorbed $\mathrm{NH}_{3}$, and $\mathrm{NH}_{3}$ adsorbed on lattice defects or terminal $\mathrm{Si}(\mathrm{OH})$ and $\mathrm{Al}(\mathrm{OH})$, whereas the high-temperature peak was assigned to the $\mathrm{NH}_{3}$ desorption from the Brønsted acid sites. The acid site density values of SP34, SP34-RS, and SP34-AS ${ }_{X}(X=0.1,0.01$, $0.001,0.0001)$ are listed in Table 1. For the SP34-RS and SP34- $\mathrm{AS}_{X}$ samples, both high- and low- temperature peaks were less intense than those of SP34, which suggested the decreasing trend of acid site density in these samples. It is well known that SAPO-34 catalysts with mild acid strength and relatively low acid site density are more appropriate for the MTO reaction ${ }^{[5]}$.

The catalytic activities of the six samples in the MTO reaction were evaluated in a fixed bed reactor at $400{ }^{\circ} \mathrm{C}$ with a methanol WHSV of $2.0 \mathrm{~h}^{-1}$, and the results were plotted in Fig. 5 and Table 1. The duration time of methanol conversion over $99 \%$ was defined as the catalytic lifetime. All catalysts synthesized in the presence of activated seeds $\left(\mathrm{SP} 34-\mathrm{AS}_{0.1}, \mathrm{SP} 34-\mathrm{AS}_{0.01}, \mathrm{SP} 34-\mathrm{AS}_{0.001}\right.$,

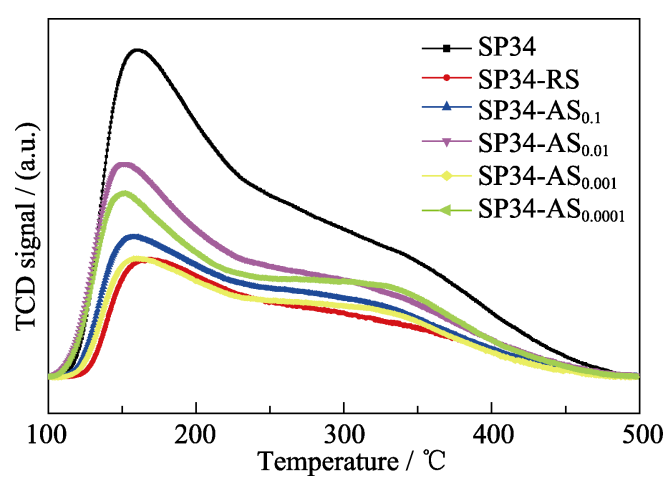

Fig. $4 \mathrm{NH}_{3}$-TPD profiles of SP34, SP34-RS and SP34-AS $(X=0.1,0.01,0.001,0.0001)$

and SP34- $\mathrm{AS}_{0.0001}$ ) exhibited remarkably prolonged catalytic lifetime (300-480 $\mathrm{min}$ ) compared to SP34 (40 min) and SP34-RS catalysts with raw seeds (100 min).

Notably, there was a large difference in the catalytic lifetime of the samples prepared by seed-assisted synthesis although they have comparable crystal size, crystallinity, and BET surface area. The catalytic lifetime order is $\mathrm{SP} 34-\mathrm{AS}_{0.1}(480 \mathrm{~min})>\mathrm{SP} 34-\mathrm{AS}_{0.001}(420 \mathrm{~min})>$ $\mathrm{SP} 34-\mathrm{AS}_{0.0001}(330 \mathrm{~min})>\mathrm{SP} 34-\mathrm{AS}_{0.01}(300 \mathrm{~min})$. This result indicated that the acid properties of SP34-AS might be the key factor affecting the catalytic lifetime. Particularly, SP34-AS $\mathrm{S}_{0.1}$ and SP34-AS $\mathrm{S}_{0.001}$ with appropriate

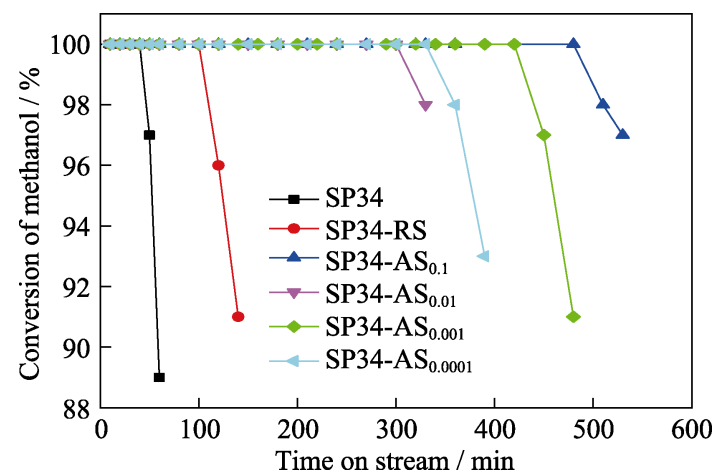

Fig. 5 Methanol conversion over SP34, SP34-RS and SP34-AS ${ }_{X} \quad(X=0.1, \quad 0.01, \quad 0.001,0.0001)$ catalysts with time-on-stream in the MTO reaction 
strong acid site density exhibited longer lifetime than SP34-AS $\mathrm{A}_{0.01}$ and SP34-AS $\mathrm{S}_{0.0001}$. This is possibly because the increased strong-acid amount (SP34-AS $\mathrm{S}_{0.01}$ and SP34-AS $\mathrm{S}_{0.0001}$ ) in SAPO-34 often causes enhanced coke formation and hydride transfer, thus leading to faster catalyst deactivation ${ }^{[43-44]}$. Therefore, the shortest lifetime of SP34 is well supported, because this catalyst possessed considerably higher strong acid site density than other catalysts. However, the catalyst with the lowest acid amount in strong acid sites, SP34-RS, did not have the longest lifetime, likely resulting from the insufficient number of acid sites, which may be rapidly covered by coke due to the diffusion limitation promoted by its low microporous surface area ${ }^{[22]}$. Therefore, in order to achieve optimal performance for the SAPO-34 catalyst, it is essential to precisely control acidity ${ }^{[13]}$ as well as diffusion properties.

\section{Conclusions}

A facile seed-assisted solvent-free approach was developed to synthesize SAPO-34 with desirable properties. The resulting SAPO-34 samples with seed crystals exhibited considerably higher crystallinity, larger surface area, but lower strong acid site density, than the parent SAPO-34. Particularly, the SAPO-34 catalysts prepared from acid-etched seed crystals showed remarkably prolonged catalytic lifetime of up to $480 \mathrm{~min}$ in the MTO reaction. The approach developed herein may open new avenues for the cost-effective fabrication of highperformance MTO catalysts.

\section{Supporting materials}

Supporting materials related to this article can be found at https://doi.org/10.15541/jim20200059

\section{References:}

[1] CORMA A. Inorganic solid acids and their use in acid-catalyzed hydrocarbon reactions. Chemical Reviews, 1995, 95(3): 559-614.

[2] AUERBACH S M, CARRADO K A, DUTTA P K. Handbook of Zeolite Science and Technology. Ashburn: CRC Press, 2003.

[3] WEITKAMP J, HUNGER M. Acid and Base Catalysis on Zeolites//ČEJKA J, van BEKKUM H, CORMA A, et al. Studies in Surface Science and Catalysis, Vol. 168, Elsevier, 2007: 787-835.

[4] STöCKER M. Methanol-to-hydrocarbons: catalytic materials and their behavior. Microporous and Mesoporous Materials, 1999, 29: 3-48.

[5] YANG M, FAN D, WEI Y, et al. Recent progress in methanol- to-olefins (MTO) catalysts. Advanced Materials, 2019, 31: 1902181.

[6] SEO G, KIM J H, JANG H G. Methanol-to-olefin conversion over zeolite catalysts: active intermediates and deactivation. Catalysis Surveys from Asia, 2013, 17(3/4): 103-118.
[7] SUN Q, XIE Z, YU J. The state-of-the-art synthetic strategies for SAPO-34 zeolite catalysts in methanol-to-olefin conversion. National Science Review, 2018, 5(4): 542-558.

[8] VAN SPEYBROECK V, DE WISPELAERE K, VAN DER MYNSBRUGGE $\mathrm{J}$, et al. First principle chemical kinetics in zeolites: the methanol-to-olefin process as a case study. Chemical Society Reviews, 2014, 43(21): 7326-7357.

[9] LIANG J, LI H, ZHAO S, et al. Characteristics and performance of SAPO-34 catalyst for methanol-to-olefin conversion. Applied Catalysis, 1990, 64: 31-40.

[10] WU P, YANG M, ZHANG W, et al. Synthesis of SAPO-34 nanoaggregates with the assistance of an inexpensive three-in-one non-surfactant organosilane. Chemical Communications, 2017, 53(36): 4985-4988.

[11] AGHAEI E, HAGHIGHI M. Effect of crystallization time on properties and catalytic performance of nanostructured SAPO-34 molecular sieve synthesized at high temperatures for conversion of methanol to light olefins. Powder Technology, 2015, 269: 358-370.

[12] LI Z, MARTINEZ-TRIGUERO J, CONCEPCION P, et al. Methanol to olefins: activity and stability of nanosized SAPO-34 molecular sieves and control of selectivity by silicon distribution. Physical Chemistry Chemical Physics, 2013, 15(35): 14670-14680.

[13] WANG C, YANG M, TIAN P, et al. Dual template-directed synthesis of SAPO-34 nanosheet assemblies with improved stability in the methanol to olefins reaction. Journal of Materials Chemistry A, 2015, 3(10): 5608-5616.

[14] WANG P, LÜ A, HU J, et al. The synthesis of SAPO-34 with mixed template and its catalytic performance for methanol to olefins reaction. Microporous and Mesoporous Materials, 2012, 152: $178-184$.

[15] SUN Q, WANG N, XI D, et al. Organosilane surfactant-directed synthesis of hierarchical porous SAPO-34 catalysts with excellent MTO performance. Chemical Communications, 2014, 50(49): 6502-6505.

[16] GUISNET M, COSTA L, RIBEIRO F R. Prevention of zeolite deactivation by coking. Journal of Molecular Catalysis A: Chemical, 2009, 305: 69-83.

[17] DAI W, LI N, LI L, et al. Unexpected methanol-to-olefin conversion activity of low-silica aluminophosphate molecular sieves. Catalysis Communications, 2011, 16(1): 124-127.

[18] OLSBYE U, BJøRGEN M, SVELLE S, et al. Mechanistic insight into the methanol-to-hydrocarbons reaction. Catalysis Today, 2005, 106(1): 108-111.

[19] DAI W, WANG X, WU G, et al. Methanol-to-olefin conversion catalyzed by low-silica AlPO-34 with traces of Brønsted acid sites: combined catalytic and spectroscopic investigations. ChemCatChem, 2012, 4(9): 1428-1435.

[20] DAHL I M, KOLBOE S. On the reaction mechanism for hydrocarbon formation from methanol over SAPO-34: 2. Isotopic labeling studies of the co-reaction of propene and methanol. Journal of Catalysis, 1996, 161(1): 304-309.

[21] HEREIJERS B P, BLEKEN F, NILSEN M H, et al. Product shape selectivity dominates the methanol-to-olefins (MTO) reaction over H-SAPO-34 catalysts. Journal of Catalysis, 2009, 264(1): 77-87.

[22] WILSON S, BARGER P. The characteristics of SAPO-34 which influence the conversion of methanol to light olefins. Microporous and Mesoporous Materials, 1999, 29(1/2): 117-126.

[23] DAHL I M, MOSTAD H, AKPORIAYE D, et al. Structural and chemical influences on the MTO reaction: a comparison of chabazite and SAPO-34 as MTO catalysts. Microporous and Mesoporous Materials, 1999, 29(1/2): 185-190.

[24] IZADBAKHSH A, FARHADI F, KHORASHEH F, et al. Effect of SAPO-34's composition on its physico-chemical properties and 
deactivation in MTO process. Applied Catalysis A: General, 2009, 364(1): 48-56.

[25] KANG M. Methanol conversion on metal-incorporated SAPO-34s (MeAPSO-34s). Journal of Molecular Catalysis A: Chemical, 2000, 160(2): 437-444.

[26] MIRZA K, GHADIRI M, HAGHIGHI M, et al. Hydrothermal synthesize of modified $\mathrm{Fe}, \mathrm{Ag}$ and $\mathrm{K}-\mathrm{SAPO}-34$ nanostructured catalysts used in methanol conversion to light olefins. Microporous and Mesoporous Materials, 2018, 260: 155-165.

[27] HUANG H, WANG H, ZHU H, et al. Enhanced ethene to propene ratio over Zn-modified SAPO-34 zeolites in methanol-to-olefin reaction. Catalysis Science \& Technology, 2019, 9(9): 2203-2210.

[28] INUI T, PHATANASRI S, MATSUDA H. Highly selective synthesis of ethene from methanol on a novel nickelsilicoaluminophosphate catalyst. Chemical Communications, 1990, 205-206.

[29] VAN NIEKERK M J, FLETCHER J C, O'CONNOR C T. Effect of catalyst modification on the conversion of methanol to light olefins over SAPO-34. Applied Catalysis A: General, 1996, 138: 135-145.

[30] MEES F D, DER VOORT P V, COOL P, et al. Controlled reduction of the acid site density of SAPO-34 molecular sieve by means of silanation and disilanation. The Journal of Physical Chemistry B, 2003, 107(14): 3161-3167.

[31] HIDAKA T, YOKOSE E. Catalysts for Methanol Conversion Reactions. Taiwan Patent, TW87111286A, 1997

[32] SUN Q, WANG N, BAI R, et al. Seeding induced nano-sized hierarchical SAPO-34 zeolites: cost-effective synthesis and superior MTO performance. Journal of Materials Chemistry A, 2016, 4(39): 14978-14982.

[33] GAO B, YANG M, QIAO Y, et al. A low-temperature approach to synthesize low-silica SAPO-34 nanocrystals and their application in the methanol-to-olefins (MTO) reaction. Catalysis Science \& Technology, 2016, 6(20): 7569-7578.

[34] WU Q, MENG X, GAO X, et al. Solvent-free synthesis of zeolites: mechanism and utility. Accounts of Chemical Research, 2018,
51(6): 1396-1403.

[35] JIN Y, SUN Q, QI G, et al. Solvent-free synthesis of silicoaluminophosphate zeolites. Angewandte Chemie-International Edition, 2013, 52(35): 9172-9175.

[36] NAJAFI N, ASKARI S, HALLADJ R. Hydrothermal synthesis of nanosized SAPO-34 molecular sieves by different combinations of multi templates. Powder Technology, 2014, 254: 324-330.

[37] MENG X, JIN Y, SUN Q, et al. Solid-state Grinding Synthesis for SAPO-34. China Patent, CN201310047582.4, 2013.

[38] MAJANO G, DARWICHE A, MINTOVA S, et al. Seed-induced crystallization of nanosized Na-ZSM-5 crystals. Industrial \& Engineering Chemistry Research, 2009, 48(15): 7084-7091.

[39] REN N, YANG Z J, LV X C, et al. A seed surface crystallization approach for rapid synthesis of submicron ZSM-5 zeolite with controllable crystal size and morphology. Microporous and Mesoporous Materials, 2010, 131(1): 103-114.

[40] QIN Z, PINARD L, BENGHALEM M A, et al. Preparation of single crystals "house-of-cards"-like ZSM-5 and their performance in ethanol-to-hydrocarbons conversion. Chemistry of Materials, 2019, 31(13): 4639-4648.

[41] LYU M, YANG C, LIU Z, et al. Atmospheric pressure synthesis of nano-scale SAPO-34 catalysts for effective conversion of methanol to light olefins. Sustainable Energy \& Fuels, 2019, 3(11): 3101-3108.

[42] SENA F C, DE SOUZA B F, DE ALMEIDA N C, et al. Influence of framework composition over SAPO-34 and MeAPSO-34 acidity. Applied Catalysis A: General, 2011, 406(1): 59-62.

[43] WANG P, YANG D, JIE H U, et al. Synthesis of SAPO-34 with small and tunable crystallite size by two-step hydrothermal crystallization and its catalytic performance for MTO reaction. Catalysis Today, 2013, 212: 62. e61-62. e68.

[44] SUN Q, MA Y, WANG N, et al. High performance nanosheet-like silicoaluminophosphate molecular sieves: synthesis, 3D EDT structural analysis and MTO catalytic studies. Journal of Materials Chemistry A, 2014, 2(42): 17828-17839.

\title{
活化晶种调节 SAPO-34 的性质及其对 甲醇制烯烃反应催化寿命的增强
}

\author{
张栋强, 路惠惠, 苏娜, 李贵贤, 季东, 赵新红 \\ (兰州理工大学 石油化工学院, 兰州 730050)
}

摘 要: 无溶剂法合成沸石法在多个方面优于常规水热合成法, 近年来引起广泛关注, 但是采用该方法合成的微孔 SAPO-34 沸石催化剂的催化寿命较短, 无法满足甲醇制烯烃工业应用的要求。本研究中开发了一种改良的无溶剂 法, 使用该法合成了具有优异甲醇制烯烃反应性能的 SAPO-34 催化剂。该法在合成体系中引入酸活化晶种, 通过调 节沸石晶化动力学来调控催化剂的物理化学性质。采用不同技术对无溶剂法合成的系列 SAPO-34 催化剂的结构性 质进行了分析表征。结果表明: 与未引入晶种合成的父代样品相比, 添加晶种得到的子代 SAPO-34 样品具有更高 的结晶度、比表面积及低的强酸中心密度, 对甲醇制烯烃反应的催化寿命可延长到 $480 \mathrm{~min}$, 远远优于对应的父代 样品 (40 min)。这一结果证实了无溶剂合成中晶种的使用可有效调节沸石的性质, 可见该方法在提高沸石催化性能 方面具有巨大潜力。

关 键 词: SAPO-34 沸石; 甲醇制烯烃反应; 无溶剂合成; 活化晶种

中图分类号: TQ174 文献标识码: A 
Supporting Materials:

\section{Modulation of SAPO-34 Property with Activated Seeds and its Enhanced Lifetime in Methanol to Olefins Reaction}

ZHANG Dongqiang, LU Huihui, SU Na, LI Guixian, JI Dong, ZHAO Xinhong

(School of Petrochemical Engineering, Lanzhou University of Technology, Lanzhou 730050, China)

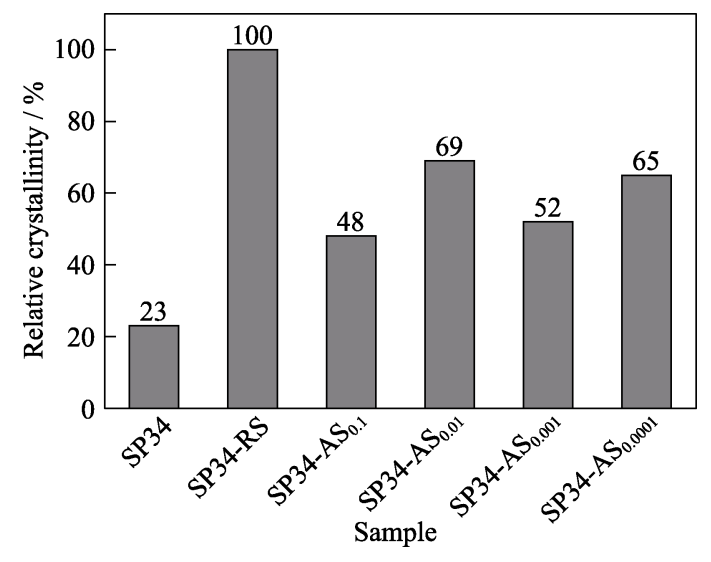

Fig. S1 Relative crystallinity of SAPO-34 synthesized in the presence of various kinds of seed crystals
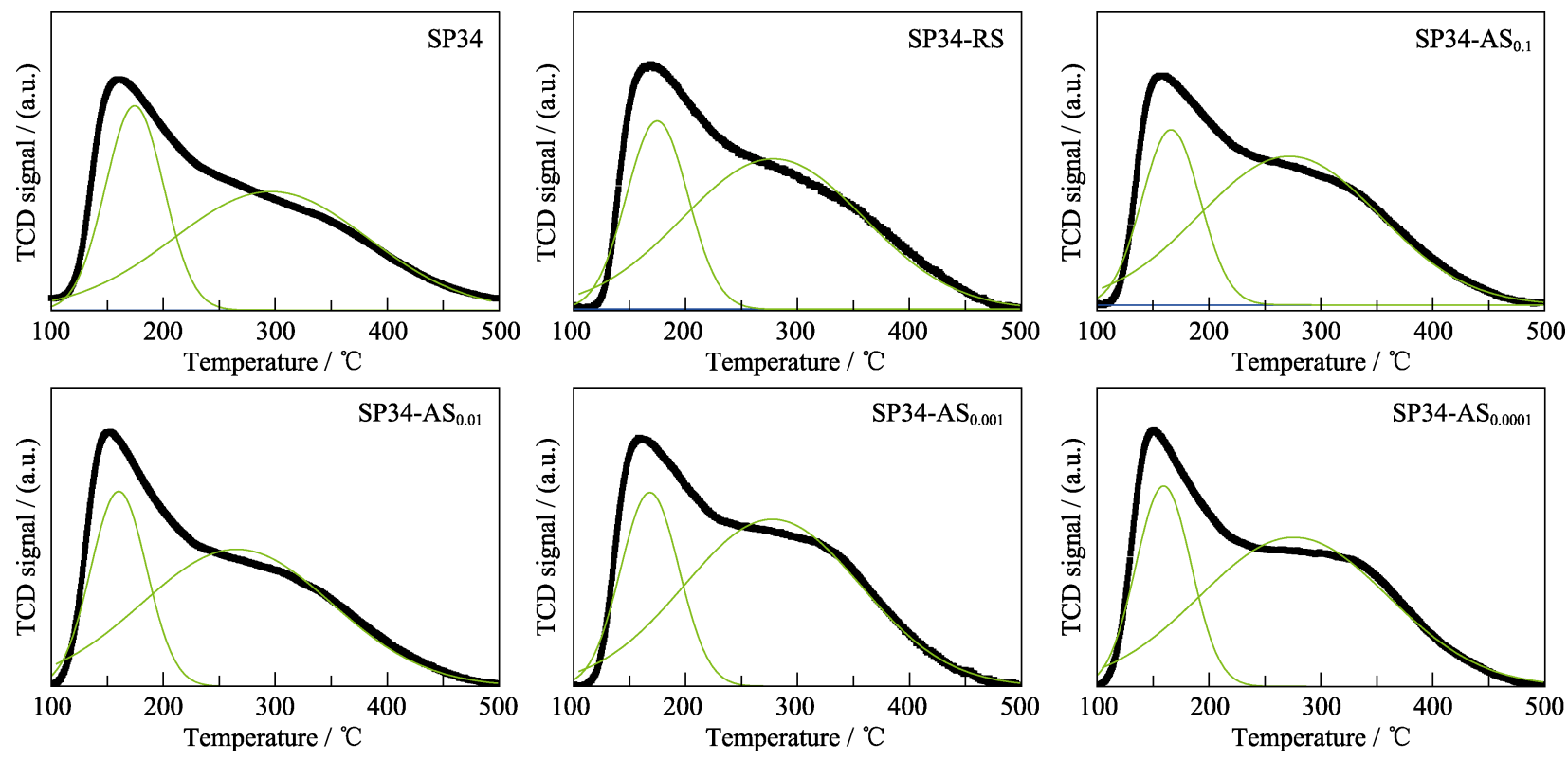

Fig. S2 Pore size distribution of SP34, SP34-RS and SP34- $\mathrm{AS}_{X}(X=0.1,0.01,0.001,0.0001)$

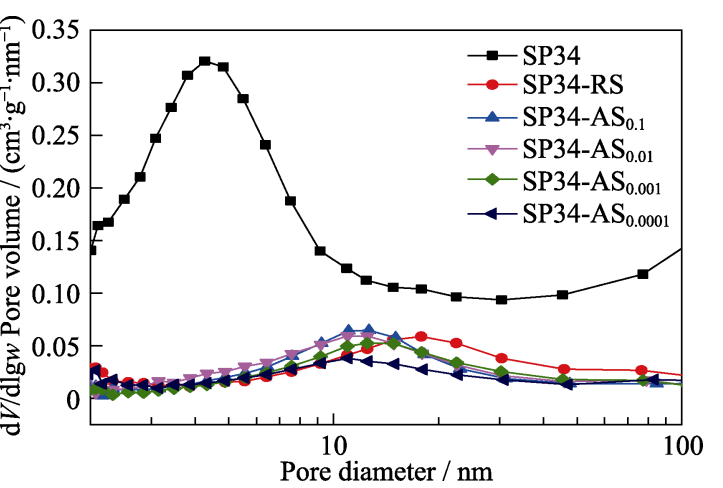

Fig. S3 Deconvolution of $\mathrm{NH}_{3}$-TPD curves of SP34, SP34-RS and SP34-AS ${ }_{X}(X=0.1,0.01,0.001,0.0001)$ 